\title{
Skin conductance as a marker of pain in infants of different gestational age
}

\author{
Jozef Macko ${ }^{\mathrm{a}}$, Dagmar Moravcikova ${ }^{\mathrm{b}}$, Lumir Kantor ${ }^{\mathrm{c}}$, Martina Kotikova ${ }^{\mathrm{a}}$, Petr Humpolicek ${ }^{\mathrm{d}, \mathrm{e}}$
}

\begin{abstract}
Aims. To assess the use of skin conductance as an objective measure of pain in infants of different gestational age. A second aim was to investigate the relationship between skin conductivity and selected physiological and behavioural variables (oxygen saturation, heart rate and behavioural state).

Methods. Infants were divided according to gestational age into the following 3 groups; group A: $25+0-31+6$ weeks (13 infants), group B: $32+0-35+6$ weeks ( 25 infants), group C: $36+0-41+6$ weeks (19 infants). The pain stimulus was blood sampling.

Results. The most sensitive parameter for describing changes in skin conductance related to pain was peak per second. No other parameter correlated with the physiological variables chosen. The results showed that the inability to determine basal skin conductance is a crucial disadvantage to practical application. The lack of correlation between conductance parameters and gestational age is surprising.

Conclusion. We conclude that the Peak per Second is the best parameter for evaluating skin conductance in infants and it is not influenced by gestational age. Peaks per Second correlate only with Prechtl's Scale of behavioural state and not with the physiological parameters chosen.
\end{abstract}

Key words: electrical skin conductivity, gestational age, infants, pain, behavioural state

Received: April 23, 2013; Accepted with revision: September 10, 2013; Available online: October 2, 2013

http://dx.doi.org/10.5507/bp.2013.066

${ }^{a}$ Department of Neonatology, Tomas Bata Regional Hospital in Zlin, Zlin, Czech Republic

${ }^{b}$ Department of Health Care Sciences, Degree Programme Midwifery, Tomas Bata University in Zlin, Zlin

'Department of Neonatology, University Hospital Olomouc, Olomouc

${ }^{d}$ Centre of Polymer Systems, Polymer Centre, Tomas Bata University in Zlin, Zlin

ePolymer Center, Faculty of Technology, Tomas Bata University in Zlin, Zlin

Coresponding author: Jozef Macko, e-mail: macko@bnzlin.cz

\section{INTRODUCTION}

The International Association of Study of Pain - IASP defines pain as „unpleasant sensorial or emotional experience which is associated with immediate or potential damage of tissue". Although more than 40 scoring schemes and pain evaluation scales have been published in the last two decades ${ }^{1-3}$ the IASP, as an international authority, recommend only the following scales: 1) Neonatal Infant Pain Scale and Premature Infant Pain Profile (PIPP) for evaluation of acute procedural pain, 2) Crying, Required O2, Increased Vital Signs, Expression, Sleeplessness for evaluation of postoperative pain, 3) Echelle Douleur Incomfort Nouveau-Né for evaluation of permanent, persisting or continuing pain. However, the problem with these scoring schemes apart from PIPP is that they do not distinguish infant gestational age ${ }^{4}$.

Measurement of changes in electrical skin conductivity (SC) appears to be a suitable method for measurement and evaluation of pain in infants as it eliminates the above problems of scoring schemes ${ }^{5,6}$. The basis of this method is the reactions of the sympathetic nervous system ${ }^{7,8}$. This is induced by painful stimuli which activate a cascade of physiological reactions resulting in sweat gland activity on the palmar side of the hand and plantar side of the foot ${ }^{9,10}$. Increase in electrical SC in these areas can be measured ${ }^{5}$. Decrease in skin resistance up to the moment of sweat reabsorption is a manifestation ${ }^{8,9}$ mea- surable as a conductivity maximum (peak). Changes in electrical SC take place almost immediately in response to painful stimulus, in about 0.7 to $2 \mathrm{sec}$ after impulse ${ }^{11}$. Measurement of electrical SC is an accepted method for assessing the new-born emotional state and is closely related to infant behaviour and crying ${ }^{12}$, which is reflected in the behavioural state of the infant according to Prechtl's method for the qualitative assessment of general movements (Prechtl's Scale) (ref. ${ }^{13,14}$ ).

The aim of this study was to determine if changes in electrical SC can be considered an objective method for measurement and assessment of pain in infants of different gestational age. A second aim was to compare these changes with changes in selected physiological parameters during painful stimulus.

\section{MATERIALS AND METHODS}

We used the Med-Storm skin conductivity algesimeter (Med-Storm Inovation, Norway) to determine SC. The "preterm" mode which is a specific setting for infants was used. The system is able to measure conductivity in the range 1 to $200 \mu \mathrm{S}$ with a noise level mainatined below $0.002 \mu \mathrm{S}$. The algesimeter is able to record any deviation or error of measurement, such as poor contact of electrodes, as well as any interference with other electrical devices. The following parameters - Peaks per Second 
$(\mathrm{PpS})$ and Area under Curve (AUC), which consist of Area Small Peaks (ASP) and Area Huge Peaks were measured. Standardly, three $\mathrm{AgCl}$ self-adhesive electrodes denoted as follows are employed: $\mathrm{C}$ - current, $\mathrm{R}$ - reference and $\mathrm{M}-$ measurement. These are placed on an area of the infant's foot, where maximum density of sweat glands can be found. The area under the $\mathrm{M}$ - the electrode is decisive for measurement as its electrical SC value reflects the amount and activity of sweat glands.

\section{Experimental}

We focused on infants from an intensive care unit, intermediary care and infants from rooming-in at the Neonatological Department of Tomas Bata Regional Hospital in Zlín, the Czech Republic. The informed consent of parents was obligatory for participation. The physiological parameters heart rate (HR) and oxygen saturation $\left(\mathrm{SatO}_{2}\right)$ were also measured. Of contextual parameters we decided to study gestational age and Prechtl's Scale of behavioural state. The infants were divided according to gestational age (GA) as follows: group A (GA-A):25+0 $31+6$ weeks ( 13 infants), group B (GA-B): $32+0-35+6$ weeks (25 infants) and group C (GA-C):36+0 - 41+6 weeks (19 infants).

According to Prechtl's Scale, infants were separated into 5 categories ${ }^{13,14}$. To prevent distortion of results we included only infants who met the criteria for categories 1 and 2. Response of the neonate to painful stimuli is significantly influenced by the state of consciousness and behaviour (sleep, wakefulness, restlessness).

Capillary blood sampling was used as the painful stimulus. Postnatal age does not play any major role in this but measurement in the case of immature infants was carried out once they had stable blood pressure and circulation. Infants whose clinical condition or therapy could affect the results of objective measurements for example worsening clinical status, increasing body temperature, decreasing $\mathrm{O}_{2}$ saturation, etc., were excluded as were infants on artificial ventilation. Feet were cleaned by normal physiological saline and the electrodes were then attached. A saturation sensor was then attached.

The experiment was divided into three phases - prestimular, stimular and post-stimular phase. In each phase, electrical SC, $\mathrm{SatO}_{2}$, HR were measured. During the prestimular phase, parameters of electrical SC were recorded for 2 min. Changes in categorization of Prechtl's scale were also recorded for each infant. Sucrose solution (25\%) in a volume $0.1-0.5 \mathrm{~mL}$ was administered to the patient at the end of this phase for about $2 \mathrm{~min}$ before blood sampling (i.e. painful stimulus). Infants received a volume of $0.1 \mathrm{~mL}$ to $1 \mathrm{~kg}$ of body weight, $0.2 \mathrm{~mL}$ to $2 \mathrm{~kg}, 0.3 \mathrm{~mL}$ to $3 \mathrm{~kg}, 0.4 \mathrm{~mL}$ to $4 \mathrm{~kg}$ and $0.5 \mathrm{~mL}$ above $4 \mathrm{~kg}$ weight. This dosage was applied on a dummy to follow the pain prevention protocol standardly used at the Neonatological department in Tomas Bata Regional Hospital in Zlín. In the second phase, the stimular phase the painful stimulus was capillary blood sampling. Recording of changes in electrical SC using Med-Storm algesimeter began simultaneously with the painful stimulus. SatO 2 and HR were measured in accordance with blood sampling. The as- sessment of Prechtl's Scale was done at the beginning and at the end of the stimular phase. All measurements were completed $1 \mathrm{~min}$ after the end of blood sampling. After termination of painful stimulus, we waited for the infants to calm down, which lasted an average of 3 - $5 \mathrm{~min}$. Through the Post-stimular phase skin conductivity changes and others parameters were recorded for one minute.

\section{Statistical analysis}

Although measurement of variables was performed for a longer period, the data from the first $15 \mathrm{~s}$ were used for statistical evaluation. Outlying data were excluded using the Q test. Tables, basic statistical parameters and Spearman correlation coefficients were done in STATISTICA software. The Mixed Linear Model was used to determine the impact of parameters on the ASP and PpS using SAS for Windows, version 9.1.2. Gestational age and interaction between phases of our test and Prechtl's Scale values were included as fixed factors into the model.

\section{RESULTS}

As can be seen from Table 1, there was no significant relation between gestational age and electrical SC values - ASP and PpS. Gestational age is thus not an important factor in the assessment of pain in infants using skin conductance.

The second aim was to investigate any relationship between skin conductivity changes, presented as parameters ASP and PpS, and selected physiological and contextual parameters (Table 2).The results showed no significant relationship between the values of $\mathrm{HR}, \mathrm{SatO}_{2}$, Prechtl's Scale and electrical SC parameters. A significant correlation was found only between ASP and PpS in all phases. Significant correlations between contextual parameter presented by Prechtl's Scale and SC parameters (ASP and $\mathrm{PpS}$ ) were found in the post-stimulaation phase only. Similar results are shown by the correlations for differences in values of parameters in different phases of the test (Table 3). From these results it is obvious that both APS and PpS have comparable validity. However, $\mathrm{PpS}$ has greater statistical significance which shows that $\mathrm{PpS}$ is a sufficient parameter for pain assessment.

Although this correlation shows the $\mathrm{PpS}$ is a better parameter for pain evaluation because there were more significant differences between $\mathrm{PpS}$ in different phases and behavioural state than ASP (Table 4). In addition we compared the SC parameters and behavioural state in individual phases of the test - before, during and after painful stimulus. As can be seen, the results show high variability of ASP values in the infants. A significant difference was found only between the pre-stimular phase with Prechtl 2 and post-stimular phase with Prechtl 1. All results unexpectedly showed low validity of the ASP indicator wrt phase of the test and behavioural state. PpS had slightly higher validity than ASP. Here the high statistical significance was in values of $\mathrm{PpS}$ between pre-stimular phase and the present value of Prechtl 1 and Prechtl 2 and 
next among pre-stimular phase with Prechtl 1 and painful phase with Prechtl 3. Therefore it is probably better to evaluate pain y using this parameter of SC. As the results show it is impossible to specify the basal skin conductivity in these short times. Continuous recording of SC in an individual infant has greater informational value and it is possible to evaluate pain via increasing frequency of peaks per second.

\section{DISCUSSION}

There are a number of publications on pain perception in infants e.g. Storm et al. ${ }^{9}$ who studied the dependence of electrical SC on painful stimuli in 20 preterm infants (29 - 35 day of gestational ages). They established that during painful stimulus the frequency of $\mathrm{PpS}$ increases while no $\mathrm{PpS}$ before or after painful stimulus was detected. This corresponds to the results of the present study as well as to another study by Storm et al. In a study published in 2008 (ref. ${ }^{15}$ ) they were unable to establish the basal line SC. They only described an increase in basal line dur- ing painful stimulus which persisted in the post-stimular phase. Harrison et al. came to the same conclusions ${ }^{16}$. Another study showing variability in skin conductivity changes ${ }^{17}$, compared skin conductivity changes with behaviour of both preterm and full term infants. The influence of both nociceptive and tactile stimulation on SC changes is described. Their results also confirm an increase in SC during nociceptive stimulus.

Perception of painful stimuli is developed in both preterm and full term infants very well. However, term infants are not used to dealing with painful stimuli. Their behaviour is just more organized ${ }^{18,19}$. Much work has been done relating to pain assessment in preterm infants. However there is currently no reliable, valid and objective physiological measure of pain in infants.

Table 1 describes how gestational age affects response to painful stimuli, ASP and PpS parameters as well. Mean values of ASP and PpS parameters across groups A to C do not differ significantly, indicating that these parameters do not depend on gestational age. Storm ${ }^{9}$ focused on dependence between parameters of gestational age and number of peaks observed as well as their amplitude. Our

Table 1. ASP and PpS according to gestational age ( $\mathrm{LSM} \pm \mathrm{SD})$.

\begin{tabular}{ccc}
\hline Gestational age & ASP & PpS \\
\hline $31+6-25+0$ (GA-A) & $0.2160 \pm 0.2352$ & $0.3117 \pm 0.0835$ \\
$35+6-32+0$ (GA-B) & $0.5512 \pm 0.2151$ & $0.3583 \pm 0.0707$ \\
$41+6-36+0$ (GA-C) & $0.5310 \pm 0.1982$ & $0.4378 \pm 0.0705$ \\
\hline
\end{tabular}

GA-A, B, C - gestational age, group A, B, C; ASP - Area Small Peaks; PpS - Peak per Second

Table 2. Spearman correlation coefficient for differences in values of studied parameters within individual phases of the test.

\begin{tabular}{|c|c|c|c|c|c|}
\hline & $\mathrm{SatO}_{2}$ & HR & Prechtl & ASP & PpS \\
\hline \multicolumn{6}{|c|}{ Pre-stimular Phase 1} \\
\hline $\mathrm{SatO}_{2}$ & 1.00 & -0.10 & -0.20 & 0.09 & 0.02 \\
\hline HR & -0.10 & 1.00 & -0.02 & -0.06 & -0.09 \\
\hline Prechtl & -0.20 & -0.02 & 1.00 & 0.08 & 0.02 \\
\hline ASP & 0.09 & -0.06 & 0.08 & 1.00 & $0.68^{*}$ \\
\hline $\mathrm{PpS}$ & 0.02 & -0.09 & 0.02 & $0.68 *$ & 1.00 \\
\hline \multicolumn{6}{|c|}{ Stimular Phase 2} \\
\hline $\mathrm{SatO}_{2}$ & 1.00 & -0.13 & -0.12 & -0.13 & -0.04 \\
\hline HR & -0.13 & 1.00 & 0.13 & -0.22 & -0.15 \\
\hline Prechtl & -0.12 & 0.13 & 1.00 & 0.25 & 0.13 \\
\hline ASP & -0.13 & -0.22 & 0.25 & 1.00 & $0.75^{*}$ \\
\hline $\mathrm{PpS}$ & -0.04 & -0.15 & 0.13 & $0.75^{*}$ & 1.00 \\
\hline \multicolumn{6}{|c|}{ Post-stimular Phase 3} \\
\hline $\mathrm{SatO}_{2}$ & 1.00 & 0.08 & -0.26 & -0.15 & -0.10 \\
\hline HR & 0.08 & 1.00 & 0.14 & -0.05 & 0.02 \\
\hline Prechtl & -0.26 & 0.14 & 1.00 & $0.39 *$ & $0.37 *$ \\
\hline ASP & -0.15 & -0.05 & $0.39 *$ & 1.00 & $0.90^{*}$ \\
\hline $\mathrm{PpS}$ & -0.10 & 0.02 & $0.37^{*}$ & $0.90^{*}$ & 1.00 \\
\hline
\end{tabular}

Marked correlation are significant on level of provability $P<0.05$

$\mathrm{SatO}_{2}$ - oxygen saturation; HR - heart rate; Prechtl - Prechtl's Scale; ASP - Area Small Peaks; PpS - Peak per Second 
Table 3. Spearman correlation coefficient for differences in values of studied parameters between individual phases of the test.

\begin{tabular}{|c|c|c|c|c|c|}
\hline & $\mathrm{SatO}_{2} 2-1$ & HR 2-1 & Prechtl 2-1 & ASP 2-1 & PpS 2-1 \\
\hline $\mathrm{SatO}_{2} 2-1$ & 1.00 & 0.19 & 0.08 & -0.23 & $-0.33 *$ \\
\hline HR 2-1 & 0.19 & 1.00 & 0.07 & -0.14 & -0.07 \\
\hline Prechtl 2-1 & 0.08 & 0.07 & 1.00 & 0.12 & 0.16 \\
\hline ASP 2-1 & -0.23 & -0.14 & 0.12 & 1.00 & $0.51 *$ \\
\hline \multirow[t]{2}{*}{ PpS 2-1 } & $-0.33^{*}$ & -0.07 & 0.16 & 0.51 * & 1.00 \\
\hline & $\mathrm{SatO}_{2} 2-3$ & HR 2-3 & Prechtl 2-3 & ASP 2-3 & PpS 2-3 \\
\hline $\mathrm{SatO}_{2} 2-3$ & 1.00 & 0.00 & 0.05 & -0.16 & -0.13 \\
\hline HR 2-3 & 0.00 & 1.00 & 0.08 & -0.01 & -0.24 \\
\hline Prechtl 2-3 & 0.05 & 0.08 & 1.00 & 0.17 & 0.08 \\
\hline ASP 2-3 & -0.16 & -0.01 & 0.17 & 1.00 & $0.46^{*}$ \\
\hline \multirow[t]{2}{*}{ PpS 2-3 } & -0.13 & -0.24 & 0.08 & $0.46^{*}$ & 1.00 \\
\hline & $\mathrm{SatO}_{2} 1-3$ & HR 1-3 & Prechtl 1-3 & ASP 1-3 & PpS 1-3 \\
\hline $\mathrm{SatO}_{2}$ 1-3 & 1.00 & 0.15 & -0.21 & 0.05 & -0.17 \\
\hline HR $1-3$ & 0.15 & 1.00 & -0.06 & -0.22 & -0.26 \\
\hline Prechtl 1-3 & -0.21 & -0.06 & 1.00 & 0.13 & 0.26 \\
\hline ASP $1-3$ & 0.05 & -0.22 & 0.13 & 1.00 & $0.62 *$ \\
\hline PpS 1-3 & -0.17 & -0.26 & 0.26 & $0.62^{*}$ & 1.00 \\
\hline
\end{tabular}

Marked correlation are significant on level of provability $P<0.05$

Described correlation (2-1; 2-3; 1-3) mean difference of the measured value in different phases of the test. SatO2 - oxygen saturation; HR - heart rate; Prechtl - Prechtl's Scale; ASP - Area Small Peaks; PpS - Peak per Second

Table 4. ASP a PpS according to phase and Prechtl's Scale (LSM \pm SD).

\begin{tabular}{lccl}
\hline Phase & Prechtl & ASP & \multicolumn{1}{c}{ PpS } \\
\hline Pre-stimular & 1 & $0.6786 \pm 0.2478$ & $0.2907 \pm 0.07409^{*}$ \\
Pre-stimular & 2 & $0.8158 \pm 0.2101^{*}$ & $0.4502 \pm 0.06343^{* *} \mathrm{a}$ \\
Pre-stimular & 3 & $0.04172 \pm 1.1382$ & $0.5429 \pm 0.3315$ \\
Stimular & 1 & $0.07337 \pm 0.8026$ & $0.2915 \pm 0.2355$ \\
Stimular & 2 & $0.3877 \pm 0.2531$ & $0.4058 \pm 0.07520 \mathrm{a}$ \\
Stimular & 3 & $0.7359 \pm 0.3143$ & $0.5401 \pm 0.09342^{* *} \mathrm{a}$ \\
Stimular & 4 & $0.9417 \pm 0.3303$ & $0.4228 \pm 0.09646 \mathrm{a}$ \\
Stimular & 5 & $0.2627 \pm 0.5083$ & $0.4605 \pm 0.1489 \mathrm{a}$ \\
Post-stimular & 1 & $0.3050 \pm 0.2230^{* *}$ & $0.1877 \pm 0.06729 \mathrm{~b}$ \\
Post-stimular & 2 & $0.5950 \pm 0.2309$ & $0.3903 \pm 0.06953 \mathrm{a}$ \\
Post-stimular & 3 & $0.06923 \pm 0.8020$ & $0.1155 \pm 0.2349$ \\
\hline
\end{tabular}

Different indexes in columns determine statistically provable differences $P \leq 0.1\left(^{*}{ }^{* *}\right.$ ); $P \leq 0.05$ (a.b)

stud shows no significant correlation between gestational age and $\mathrm{PpS}$ during painful stimulus, just as gestational age affects neither level of basal line of electrical SC nor behavioural state of an infant during painful stimulus.

A comparison of SC parameters with selected physiological parameters was studied by Roeggen et al. in Australia in $2011\left(\right.$ ref. $^{20}$ ). Our results (Tables 2 and 3) showed that there were no correlation between physiological parameters and SC parameters. Moreover, no correlation, either in shift of skin conductivity parameters between individual phases (Table 2) or between phases themselves (Table 3), was found. The only statistically significant correlation can be established between ASP and $\mathrm{PpS}$ values but not in relation to physiological parameters. Mutual correlation between ASP and PpS was 0.51 in phase 2-1 and 0.46 in phase 2-3 and 0.62 in phase 1-3. Statistically significant was a negative correlation between
$\mathrm{SatO}_{2}$ and $\mathrm{PpS}$ parameters $-0.33 P=0.05$, but only in shift between phases 2 and 1 (Table 3 ).

For individual phases of the test, which are described in Table 2, statistically significant correlation was found again only between parameters of SC. Correlation between ASP and PpS was 0.68 in the pre-stimular phase, 0.75 in the stimular phase and 0.90 in the post-stimular phase 3 . In addition there was a statistically significant correlation between parameters of SC and values of Prechtl behavioural state in the post-stimular phase. There was a statistically significant correlation between parameters PpS and Prechtl of 0.37 and between ASP and Prechtl of 0.39 . Storm claims that the behavioural state of an infant reflects the number of $\mathrm{PpS}$ during painful stimulus ${ }^{9}$. 


\section{CONCLUSION}

This study deals with objectification of painful stimulus evaluation in infants, in particular with relationship between skin conductivity and selected physiological parameters in different gestational categories. The results show it is necessary to focus on individual assessment during evaluation of pain in infants, as there is no universal basal level of skin conductivity. It is highly specific for given infant. We confirm the previous studies which show that only real Peaks per second have high validity for pain assessment in all gestational categories. Skin conductivity is not significantly influenced by either the phase of the test or the gestational age of infant. Likewise, it is impossible to determine basal lines of electrical skin conductivity. Data are valid only for a given individual infant. Skin conductivity changes are most probably influenced by many others factors, not exclusively by painful stimuli. However this method can assist pain assessment in infants, which due to its complexity requires a wide choice of techniques. No relationship between physiological parameters and parameters of SC was confirmed.

As a limitation of this study can be considered that we did not compare infants with and without using of analgesics. The reason for this is that it is not in accordance with our ethical principles. Another limitation is the low number of universe or that we did not compare SC with other scoring schemes of paint (e. i. PIPP), we compared it only with physiological parameters whose sensitivity and specificity, in relationship with objectification of pain perception, do not achieve of required level in infants.

\section{ABBREVIATIONS}

ASP, Area Small Peaks; AUC, Area Under Curve; GA, gestational age; GA-A, B, C, gestational age-group A, B, C; HR, heart rate; IASP, International Association of Study of Pain; PIPP, Premature Infant Pain Profile; $\mathrm{PpS}$, Peak per Second; $\mathrm{SatO}_{2}$, oxygen saturation; SC, skin conductivity.

\section{ACKNOWLEDGEMENT}

Financial support of the Czech Science Foundation (13-08944S) is gratefully acknowledged.

Authorship contributions: JM, LK: literature search; JM: manuscript writing; JM, DM: study design; JM, PH,DM, MK: data collection; JM, PH: data analysis; PH, JM, DM: data interpretation; JM, LK, PH: statistical analysis, figures; JM: final approval.

Conflict of interest statement: None Declared.

\section{REFERENCES}

1. Hudson-Barr D, Capper-Michel B, Lambert S, Palermo TM. Validation of the Pain Assessment in Neonates (PAIN) scale with the Neonatal Infant Pain Scale (NIPS). Neonatal netw 2002;21:15-21.

2. van Dijk M, deBoer JB, Koot HM, Tibboel D, Paschier J. The reliability and validity of the COMFORT scale as postoperative pain instrument in 0 to 3 year old infants. Pain 2000;84:367-77.

3. Peters JW, Koot HM, Grunau RE, de Boer J, van Druenen MJ, Tibboe D, Duivenvoorden HJ. Neonatal Facial Coding System for assessing postoperative pain in infants; item reduction is valid and feasible. Clin J Pain 2003;19:353-63.

4. Stevens B, Gibbins S, Franck LS. Treatment of pain in the neonatal intensive care unit. Pediatr Clin N Am 2000;47(3):633-50.

5. Gjerstad AN, Wagner K, Henrichsen T, Storm H. Skin conductance Versus the Modified COMFORT Sedation Score as a Measure of Discomfort in Artificially Ventilated Children. Pediatrics 2008;122:e848-e853.

6. Edelberg R. Electrical properties of the skin. In: Brown CC, eds. Methods in Psychophysiology. Baltimore, MD: Williams \&Wilkins; 1967:1-53.

7. Hagbarth $\mathrm{KE}$, Hallin RG, Hongell A, Torebjörk HE, Wallin BG. General characteristics of sympatethic activity in human skin nerves. Acta Physiol Scand 1972;84(2):164-76.

8. Wallin BG, Sundlöf G, Delius W. The effect of carotid sinus nerve stimulations on muscle and skin nerve sympathetic activity in man. Pflügers Arch 1975;358(2):101-10.

9. Storm $\mathrm{H}$. Skin conductance and the stress response from heel stick in preterm infants. Arch Dis Child Fetal Neonatal Ed 2000;83:F143-F147.

10. Gjerstad AC, Storm H, Wallin G. Evaluation of the skin conductance method by using microneurographi. (abstract) Chicago: ISAP; 2006.

11. Lidberg L, Wallin BG. Sympathetic skin nerve discharges in relation to amplitude of skin resistance responses. Psychophysiology 1981;18(3):268-70.

12. Gladman G, Chiswick ML. Skin conductance and arousal in the newborn infant. Arch Dis Child 1990;65:1063-6.

13. Prechtl HF. The behavioural states of the newborn infant (a review). Brain Res 1974;76(2):185-212.

14. Darsaklis V, Snider LM, Majnemer A, Mazer B. Predictive validity of Prechtl's Method on the Qualitative Assessment of General Movements: a systematic review of the evidence. Dev Med Child Neurol 2011;53(10):896-906.

15. Storm H. Changes in skin conductance as a tool to monitor nociceptive stimulation and pain. Curr Opin Anaesthesiol 2008;21:796-804.

16. Harrison D, Boyce S, Loughnan P, Dargaville P, Storm H, Johnston L. Skin conductance as a measure of pain and stress in hospitalised infants. Early Hum Dev 2006;82(9):603-8.

17. Hellerud BC, Storm H. Skin condutance and behaviour during sensory stimulation of preterm and term infants. Early Hum Dev 2002;70(1 - 2):35-46.

18. Holsti L, Grunau RE, Whitfield MF. Behavioural Responsivenes to pain are heightened after clustered care in preterm infants born between 30 and 32 weeks gestational age. Clin J Pain 2006;22(9):757-64

19. Morison SJ, Grunau RE, Oberlander TF, Whitfield MF. Relations between behavioral and cardiac autonomic reactivity to acute pain in preterm neonates. Clin J Pain 2001;17(4):350-8.

20. Roeggen I, Storm H, Harrison D. Skin conductance variability between and within hospitalised infants at rest. Early Hum Dev 2011;87:37-42. 